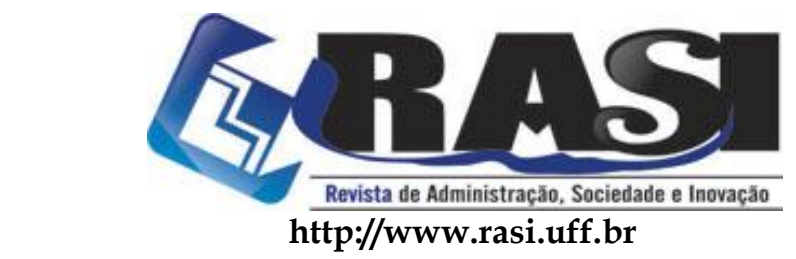

RASI, Volta Redonda/RJ, v. 2, n. 2, pp. 90-105, jul./dez. 2016

\title{
Identidade com a Carreira: a perspectiva de acadêmicos em relação ao desenvolvimento da vida profissional
}

Reginaldo Adriano de Souza, Rita de Cássia Martins de Oliveira Ventura, Carla Aparecida

Soares

\section{Resumo:}

$\mathrm{O}$ século XXI, com sua competitividade e grandes mudanças, tem exigido dos profissionais novas qualificações e habilidades. Essa busca por qualificação, associada à identidade com a carreira, contribui para formação de perspectivas em relação à trajetória profissional sendo mais uma complexidade a ser considerada. Este estudo buscou diagnosticar a existência da identidade com a carreira sob a perspectiva de estudantes do curso superior e as principais âncoras que são determinantes no direcionamento de suas trajetórias profissionais. Para operacionalizar este objetivo, realizou-se um survey com uma amostra que contemplava todos cursos ministrados por uma faculdade da zona da Mata Mineira. Com os resultados obtidos, foi possível constatar que os jovens preocupam-se em construir uma carreira tendo em vista o equilíbrio com a vida familiar, e $96 \%$ da amostra estudada, consideram que o curso corresponde à atual perspectiva de carreira que possuem. As âncoras de maior evidência foram Serviço ou Dedicação a uma Causa, Estilo de Vida e Segurança e Estabilidade. O que mais surpreendeu é que a amostra pesquisada revelou que carreira não pode e nem deve mais ser vista de maneira isolada em virtude do peso de diversas variáveis; no caso deste estudo, sobressaíram-se, as variáveis; gênero e família.

Palavras-chave: Âncoras de carreira; Estudantes; Identidade; Carreira.

\section{Identity with the career: the prospect of academics in relation to the professional life}

\begin{abstract}
:
The twenty-first century, with its competitiveness and major changes, has required of the professionals new skills and abilities.This quest for qualification associated with identity with career, contributes to the formation of perspectives on the professional career being one more complexity to be considered. This study aimed to determine the existence of identity with the career from the perspective of college students and the main anchors that are crucial in directing their professional careers. To operationalize this goal, it was conducted a survey with a sample which included all courses taught by a college in area of Zona da Mata Mineira. With the results obtained, it was found that young people are concerned in building a career owing the balance with family life, and $96 \%$ of the sample consider that the course corresponds to the current carrer perspective that they have. The greatest evidence of anchors were Service and Dedication to a Cause, Lifestyle and Security and Stability. What surprised me the most is that the sample studied revealed that career can not and should not longer be seen in isolation because of the weight of several variables; in the case of this study, they stood out, the variables; gender and family.
\end{abstract}

Keywords: Career Anchors; Students; Identity; Career.

\section{Universidade U1口 Federal Fluminense}

R. Desembargador Ellis Hermydio Figueira, 783, Bloco A, sl. 218, Aterrado. 27213-415 - Volta Redonda, RJ - Brasil www.uff.br

Copyright ( 2016 RASI. Todos os direitos, até mesmo de tradução, são reservados. É permitido citar parte de artigos sem autorização prévia, desde que seja identificada a fonte. 


\section{Identidade com a Carreira: a perspectiva de acadêmicos em relação ao desenvolvimento da vida profissional}

\section{Introdução}

Em um século de intensas transformações, nota-se em destaque a mudança do cenário que abrange o mundo do trabalho, em especial as novas formas de trabalho, os novos tipos de profissionais, as novas exigências por qualificações e, ao lado de tudo isso, a perspectiva das pessoas que se preocupam com a construção de uma carreira. Segundo O'donnel (2006), grandes são os desafios que foram trazidos pelo atual milênio, desafios esses que dizem respeito ao trabalho e a vida de funcionários de qualquer empresa.

Um desses desafios citados pelo autor acima corresponde à gestão de carreira, cujo conceito está sendo constantemente repensado e analisado. De acordo com Brown e Lent (2008), nos últimos vinte anos, ocorreu uma proliferação literária em relação à orientação e ao desenvolvimento de carreira, evidenciando as grandes dimensões que o assunto tem adquirido.

Porém, não são somente mudanças relativas ao trabalho ou a carreira que têm marcado as últimas décadas, mas também a mudança no perfil do capital intelectual disponível no que se refere à busca de qualificação em cursos de formação superior. Essa busca por qualificação, associada à identidade com a carreira, contribui para a formação de perspectivas em relação à trajetória profissional, sendo mais uma complexidade a ser considerada.

De acordo com Robbins (1998), a evolução do conceito de carreira é recente e o formalizado plano de carreira dirigido pelo empregador já não é mais utilizado, cedendo lugar às carreiras autodirigidas.

Vale ressaltar também os valores individuais que as pessoas prezam ou desenvolvem ao investir em uma carreira. Segundo Schein (1996a), as escolhas profissionais de um indivíduo baseiam-se em um conjunto de valores, motivos e competências, denominados âncoras.

Diante destes aportes teóricos, estabeleceu-se como objetivo geral deste estudo diagnosticar a existência da identidade com a carreira sob a perspectiva de estudantes do ensino superior e as principais âncoras que são determinantes no direcionamento de suas trajetórias profissionais.

Para operacionalizar esse objetivo, realizou-se um survey tendo como população os discentes de uma faculdade da zona da Mata Mineira. Os resultados obtidos apontam de uma forma geral, que apesar de se verificar o interesse que os pesquisados possuem em construir uma carreira, esta não é a prioridade dos mesmos. Esse fato alerta para o fato de mais estudos diante de um constructo tão instigante como é a carreira e suas âncoras.

\section{Carreira e seus Aportes Teóricos}

Hall (1976) define carreira como uma relação das atitudes e comportamentos durante o período de vida de uma pessoa, associada com as experiências e as atividades do trabalho.

O conhecimento sobre o termo carreira é recente, segundo Chanlat (1995), foi com a sociedade industrial, marcada pelas ideias de liberdade do êxito individual, 
igualdade, progresso econômico e social que fez com que fazer carreira tornou-se possível, teoricamente, para todos. Já que anteriormente, no período feudal, a mobilidade social só acontecia se houvesse boa vontade dos monarcas e, ainda, com a condição de respeitar às estruturas aristocráticas.

Kilimnik (2000) aponta dois modelos de carreira, o primeiro considerado tradicional baseado em uma sociedade estável, com divisão sexual e social do trabalho nítidas e o segundo menos tradicional, resultante de mudanças sociais, caracterizado pela inserção crescente das mulheres no mercado de trabalho, elevação dos graus de instrução, globalização da economia, afirmação dos direitos individuais, flexibilização do trabalho, dentre outras.

Em complementaridade ao conceito de carreira surgiu o plano de carreira que segundo Lucena (1999), é voltado para as expectativas e interesses dos indivíduos no que tange aos seus objetivos profissionais e aspirações pessoais quanto à carreira.

Foi após a Segunda Guerra Mundial que o destaque dado aos planos de carreira (PC), teve notoriedade, tendo suas bases, nascidas com a Escola da Administração Científica, a partir do estabelecimento de cargos ligados aos postos de trabalho e dos sistemas de diferenciação entre eles (Dutra, 1996). Nesse período, o perfil profissional exigido era extremamente funcional, trabalhadores pagos para fazer e não para pensar, sendo o plano de carreira de responsabilidade das organizações (Araújo, 2009).

Com o passar do tempo, mudanças ocorreram e, atualmente, muitas organizações já transferiram a responsabilidade de gerir a carreira para as pessoas, pois hoje "criatividade, motivação e envolvimento (a partir de uma grande identidade entre indivíduo e empresa) são peças chaves para produzir de acordo com as necessidades organizacionais" (Irisvideo, 1995, sp) [sic].

Nesse contexto, a identidade, segundo Araújo (2009), é crucial para o desenvolvimento da carreira, uma vez que explica e tem como consequência a motivação própria e o envolvimento que se espera da empresa com o seu corpo funcional. A identidade não releva necessariamente a remuneração e "antecede tudo em um plano de carreira que pretende ser decisivo na trajetória do quadro funcional da organização" (Araujo, 2009, p. 129). A identidade representa a construção ontológica de uma pessoa e revela, em parte, o controle que a mesma tem sobre sua mobilidade profissional (Malvezzi, 2000).

Na década de 1970, Schein (1978) enfatizou que a essência do desenvolvimento da carreira está pautada na relação entre os interesses do indivíduo e da organização. $\mathrm{O}$ autor divide o conceito de carreira entre carreira interna e carreira externa. A carreira externa definida pelas etapas exigidas para se obter progresso na profissão ou na organização. Já a carreira interna, volta-se para a percepção que o indivíduo possui sobre o desenvolvimento de sua vida profissional. Em seus estudos, Schein (1978) observou a existência de elementos comuns quanto ao modo com que as pessoas de diferentes ocupações percebem as tarefas e os estágios de sua carreira. Tais aspectos foram denominados pelo autor como "âncoras de carreira".

\section{1 Âncoras de Carreira}

"Uma âncora de carreira é um autoconceito que orienta, estabiliza e integra as experiências profissionais de uma pessoa" (Milkovich \& Boudreau, 2000).

Schein (1978) define âncora de carreira como a combinação das autopercepções sobre talentos e habilidades, motivos, necessidades e valores que as pessoas possuem 
em relação ao trabalho que desenvolvem ou buscam desenvolver. O referencial sobre âncoras, desenvolvido por Edgar Schein, é o mais completo entre as abordagens que tratam sobre a temática, além de estar em harmonia com o fato das carreiras na atualidade serem autodirigidas.

O conceito nasceu de uma pesquisa longitudinal realizada por Schein no período entre 1961 e 1973, através de um processo de reentrevista com quarenta e quatro profissionais que haviam concluído a graduação. O objetivo de Schein era compreender a evolução das carreiras, a percepção que as pessoas tinham a respeito dessa evolução, focalizando a história da vida profissional de cada um dos entrevistados, as razões de suas escolhas e tomada de decisões (Schein, 1978, 1996b).

Por meio das análises do resultado de seus estudos, Schein encontrou oito âncoras de carreira, as quais seguem descritas a seguir de acordo com suas particularidades, tendo por base as obras do autor (1978, 1996a, 1996b).

- Âncora Competência Técnica-Funcional: engloba trabalhadores que valorizam o desafio em sua área de atuação e organizam suas carreiras em torno de suas áreas técnicas específicas, buscando aperfeiçoar suas aptidões nessas áreas. Essas pessoas não valorizam promoções que as afastem de suas especialidades e se interessam por promoções que lhes atribuam mais responsabilidades e recursos.

- Âncora Competência para o Gerenciamento (Administração Geral): pessoas qualificadas por essa âncora desejam ascensão hierárquica e valorizam o fato de exercerem importantes responsabilidades e liderarem, tendo em vista relacionar seus esforços com os sucessos da organização. Valorizam a promoção por mérito e desempenho e a mobilidade vertical dentro das organizações.

- Âncora Segurança e Estabilidade: identificam-se nessa âncora, o grupo de pessoas que valorizam a estabilidade da carreira e a segurança, têm interesse em trabalhar em organizações consolidadas e confiáveis, com baixas taxas de rotatividade e com programas de benefícios. Valorizam a promoção previsível por tempo de serviço e desempenho.

- Âncora Criatividade Empreendedora: nessa categoria foram incluídas pessoas com perfis voltados para a necessidade de construir algo advindo de seus esforços. Essas pessoas buscam atividades em que posam expressar sua criatividade e tendem a não permanecer em organizações tradicionais. Valorizam o fato de terem sua propriedade (ações, patentes, produto por elas criados etc.) e, no que se refere à mobilidade, querem promoções que lhes deem autonomia e poder para exercerem a criatividade.

- Âncora Autonomia e Independência: refere-se a pessoas que dão ênfase à liberdade para o desenvolvimento de suas competências técnicas e funcionais. Rejeitam organizações que impõem regras e normas, uma vez que gostam de realizar as atividades de acordo com um padrão próprio. Valorizam benefícios móveis, não atrelados à estabilidade, e remuneração por mérito de seu desempenho. Muitas vezes, valorizam mais o reconhecimento do que a promoção em si, uma vez que ser promovido pode implicar tanto no aumento da liberdade quanto na perda de autonomia.

- Âncora Serviço ou Dedicação a uma Causa: essa âncora inclui pessoas que valorizam servir a uma causa em prol da melhoria da sociedade e não dão muita relevância ao dinheiro em si, mas esperam remunerações justas por sua 
contribuição. Anseiam por promoções a cargos com autonomia e influência, e prezam o reconhecimento pela organização.

- Âncora Desafio Puro: as pessoas identificadas nessa âncora são determinadas a vencer desafios, solucionar problemas e superar situações adversas. Costumam ser inflexíveis e querem ter suas habilidades colocadas à prova no ambiente de trabalho.

- Âncora Estilo de Vida: abordando uma tendência em ascensão, essa âncora refere-se às pessoas que buscam equilíbrio entre a carreira, a vida pessoal e a familiar. $\mathrm{O}$ grupo pertencente a essa âncora valoriza a flexibilidade, e uma visão organizacional que reflita interesse pela vida pessoal e familiar dos colaboradores. O desejo por crescimento profissional, remuneração, reconhecimento e desenvolvimento da carreira variam de acordo com as necessidades individuais dos que pertencem a essa âncora.

\section{Método de Pesquisa}

O intuito deste estudo foi diagnosticar a existência da identidade com a carreira sob a perspectiva de estudantes do ensino superior e as principais âncoras que são determinantes no direcionamento de suas trajetórias profissionais. Para tanto optou-se por realizar a pesquisa em uma faculdade na Zona da Mata Mineira que possui 13 cursos de graduação presencial atendendo a um público de 914 alunos. O período de coleta de dados ocorreu durante o segundo semestre do ano letivo de 2012.

Para atender ao objetivo, realizou-se uma pesquisa descritiva, uma vez que esse tipo de pesquisa destaca-se por trabalhar com o levantamento de opiniões, críticas, atitudes, percepções e crenças de um grupo de pessoas e permite associações entre variáveis e preferências encontradas quanto ao resultado da pesquisa (Gil, 1999).

Quanto ao meio empregado, de acordo com Bertucci (2009), a pesquisa classifica-se como um survey. Os surveys oferecem a possibilidade de descrever, explicar ou explorar determinado fenômeno, possibilitando alcançar um grande número de pessoas e evitando que o pesquisador sofra influência de opiniões e aspectos pessoais dos entrevistados.

Para a coleta de dados, utilizou-se como instrumento o "Inventario de Orientação de Carreira", desenvolvido por Edgar Schein (1996a), com a finalidade de identificar quais âncoras de carreiras têm sido determinantes no direcionamento das trajetórias profissionais de discentes provenientes de curso superior.

O inventário de carreira é composto por quarenta afirmativas, cuja veracidade é julgada pelo participante da pesquisa de acordo com o que o mesmo considerar pertinente. As atribuições são dadas em uma escala de um a seis, onde 1 representa o grau de maior discordância da afirmativa apresentada ("Jamais se aplica a você") e 6 apresenta o maior grau de concordância da afirmativa em questão ("Sempre se aplica a você").

Com o intuito de se delinear melhor os resultados, juntamente com o questionário, optou-se por utilizar questões abertas em uma folha de resposta para diagnosticar características como sexo, idade, curso etc., e variáveis que possivelmente possam ter relação com as âncoras de carreira e a importância da identidade dentro da profissão.

Para a caracterização da amostra de pesquisa, optou-se pelo método de amostragem sistemática, método esse que se trata de uma variação da amostragem 
aleatória simples, recomendado quando se tem disponível uma lista de elementos ordenados segundo algum critério (Fonseca \& Martins, 2008). O intervalo da amostra sistemática é dado através do seguinte cálculo:

$$
\begin{aligned}
& a=\frac{N}{n} \\
& \text { Onde: } \\
& a=\text { intervalo da amostra } \\
& \mathrm{N}=\text { tamanho total da população } \\
& \mathrm{n}=\text { tamanho desejado da amostra }
\end{aligned}
$$

Após obter-se o valor de "a", escolhe-se ou sorteia-se aleatoriamente um número $\mathrm{x}$ entre $1 \mathrm{e}$ " $\mathrm{a}$ ", para formar a amostra, ficando a amostra constituída a partir de $\mathrm{x} ; \mathrm{x}+\mathrm{a}$; $\mathrm{x}+2 \mathrm{a} ; \ldots$

O tamanho total da amostra disponível para essa pesquisa é de 914 alunos, distribuídos entre 13 cursos de graduação, sendo que se desejava trabalhar com $10 \%$ da amostra total como base para a projeção dos resultados, sendo assim, calculou-se:

$914 \times 10 \%=91,4$ que, utilizando-se a técnica do arredondamento, ficou definida a quantidade de 91. Logo, tomando como base o cálculo da amostra sistemática, obtevese o seguinte resultado.

$$
\mathrm{a}=\frac{914}{91}=10
$$

Entre 1 e 10 foi selecionado o número 10 para o início da amostra; sendo assim, os elementos da população de número $10,20,30, \ldots 910$ compuseram a amostra com a qual se trabalhou com aplicação dos questionários e por meio da qual foi feita a projeção dos resultados obtidos para a população total.

Os resultados obtidos por meio do Inventário de Orientação de Carreira foram tabulados no programa Microsoft Excel, em forma de banco de dados, analisando-se a frequência de âncoras encontradas na amostra geral e por curso; além da possível associação dela com o curso, utilizando-se, para isso, a medida de desvio padrão.

\section{Análise dos Resultados}

Em relação ao perfil geral dos pesquisados, verificou-se que $58 \%$ são do sexo feminino e $42 \%$ do sexo masculino. Com relação à idade, $46 \%$ estão na faixa de 18 a 21 anos, $26 \%$ na faixa de 22 a 25 anos, $18 \%$ na faixa de 26 a 30 anos e $10 \%$ na faixa acima de 30 anos. Quanto ao estado civil 71\% são solteiros e $29 \%$ são casados. Quando questionados sobre o curso corresponder à perspectiva que possuem de carreira, $96 \%$ afirmaram que o curso corresponde à perspectiva que possuem sobre carreira, e apenas $4 \%$ afirmaram o contrário, que o curso não corresponde à perspectiva que possuem sobre carreira. Quanto a considerar prioridade entre carreira e família, 4\% consideram carreira como prioridade, $40 \%$ consideram família como prioridade e $56 \%$ consideram ambos, carreira e família, com o mesmo grau de prioridade.

Verificou-se também que $81 \%$ dos pesquisados exercem ou exerceram algum tipo de atividade remunerada e $19 \%$ deles nunca trabalharam. Do percentual que 
exercem atividade remunerada, $74 \%$ se identificam com o cargo ou profissão atual que exercem, $23 \%$ não se identificam e $3 \%$ não responderam se existia identificação. Verificou-se ainda que $47 \%$ dos pesquisados contam com experiência profissional de 1 a 5 anos, $31 \%$ de 6 a 10 anos e $22 \%$ maior que 10 anos.

A FIGURA 1 ilustra a frequência encontrada para cada âncora de carreira:

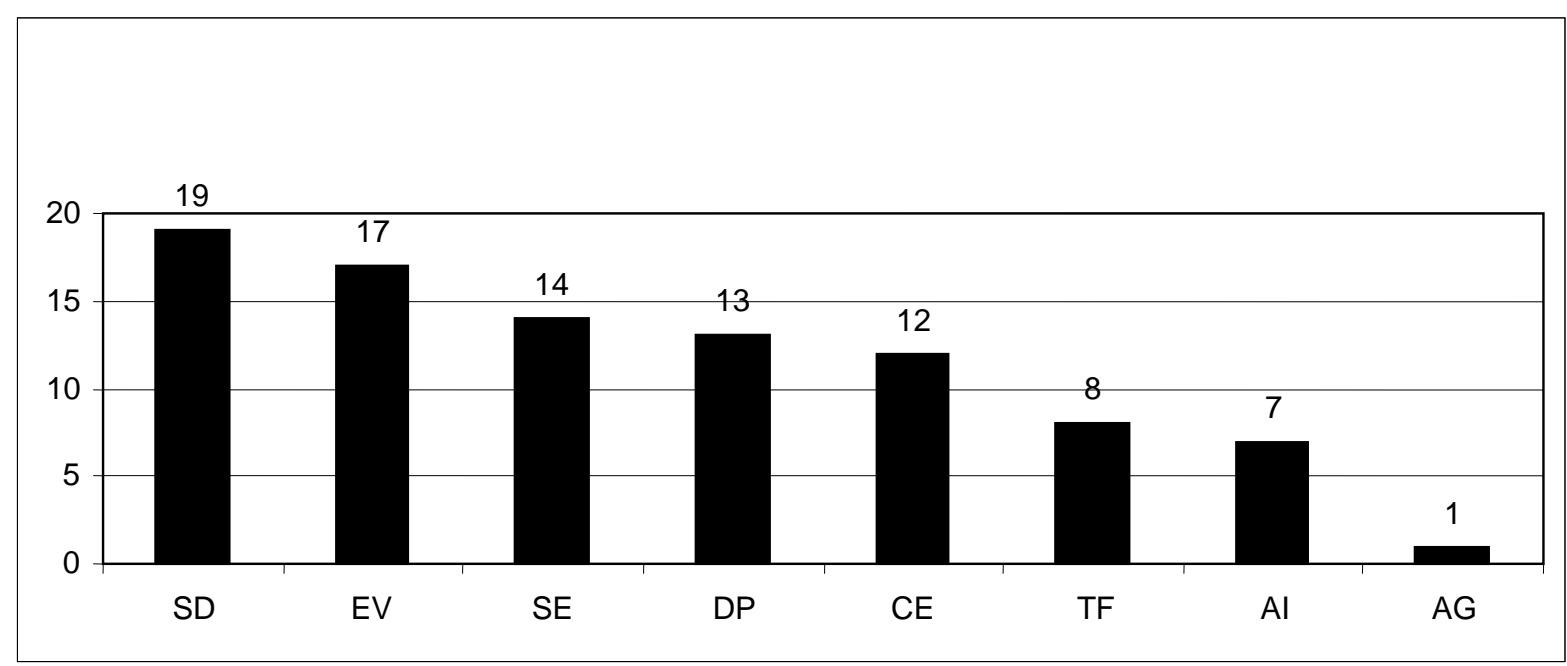

SD: Serviço ou Dedicação a uma Causa; EV: Estilo de Vida; SE: Segurança e Estabilidade; DP: Desafio Puro; CE: Criatividade Empreendedora; TF: Competência Técnica-Funcional; AI: Autonomia e Independência; AG: Administração Geral.

Figura 1: Distribuição de frequência das âncoras encontradas na amostra geral, independente do curso Fonte: Dados de pesquisa.

Analisou-se, nesse primeiro momento, a frequência de âncoras sem relacionar os cursos envolvidos no estudo com o objetivo de identificar as âncoras determinantes dos acadêmicos pesquisados, o que permite dizer que, de um modo geral, as âncoras determinantes das trajetórias profissionais de jovens acadêmicos têm sido Serviço ou Dedicação a uma Causa (20\%) e Estilo de Vida (19\%).

$\mathrm{Na}$ folha de respostas utilizadas na pesquisa, buscou-se conhecer se os respondentes se identificavam com o cargo ou profissão atual, sendo a resposta sim ou não, foram solicitadas três justificativas. As justificativas, de modo geral, que mais se destacaram foram: a possibilidade de lidar com o público, autonomia e poder de decisão e satisfação pessoal no que executam. Foi verificado que, dos pertencentes à âncora Serviço ou Dedicação a uma Causa, em suas justificativas sobre a identidade com o cargo ou profissão, sempre respondiam que valorizam autonomia e poder de decisão ou o prazer por lidarem com pessoas.

A âncora de menor destaque foi a Administração Geral, apenas um pesquisado se enquadrou nessa categoria, resultado considerado intrigante, já que a maioria da amostra foi composta por graduandos de Administração.

A baixa frequência dessa âncora pode estar associada ao fato da pequena experiência profissional dos entrevistados, a maioria situa-se na faixa de 1 a 5 anos de experiência (47\%) e ao fato da maioria $(71 \%)$ ser solteiros.

A Tabela 1 mostra a frequência das âncoras encontradas e o desvio padrão correspondente ao resultado. 
TABELA 1: Desvio padrão entre as âncoras encontradas independente do curso

\begin{tabular}{llll}
\hline Categoria & Frequencia & $(\%)$ & $(\%)$ Cumulativa \\
\hline TF & 8 & 9 & 9 \\
AG & 1 & 1 & 10 \\
AI & 7 & 8 & 18 \\
SE & 14 & 15 & 33 \\
CE & 12 & 13 & 46 \\
SD & 19 & 21 & 67 \\
DP & 13 & 14 & 81 \\
EV & 17 & 19 & 100 \\
Total & 91 & & \\
\hline Desvio Padrão & 5.8 & &
\end{tabular}

O desvio padrão revela uma dispersão de 5.8 para a amostra. Contudo verificouse que $96 \%$ dos pesquisados disseram que o curso corresponde às suas perspectivas de carreira; desses, $81 \%$ possuem experiência profissional, estando $74 \%$ identificados com o atual cargo ocupado ou profissão, portanto, vale afirmar que o resultado obtido pela maioria das âncoras realmente reflete o direcionamento de carreira desses indivíduos.

\section{TABELA 2: Características da amostra por curso}

\begin{tabular}{lllllll}
\hline Categorias & Total & Homens & Mulheres & Solteiros & Casados & Âncora em destaque \\
\hline Administração & 24 & 14 & 10 & 22 & 2 & SD/EV \\
Arquitetura e Urbanismo o & 9 & 6 & 3 & 6 & 3 & CE \\
Gestão Ambiental & 3 & 3 & 0 & 3 & 0 & DP \\
Contabilidade & 13 & 8 & 5 & 5 & 8 & EV \\
Direito & 8 & 5 & 3 & 6 & 2 & TF \\
Construção de Edifícios & 1 & 0 & 1 & 1 & 0 & $*$ \\
Engenharia Civil & 12 & 5 & 7 & 8 & 4 & DP \\
História & 4 & 2 & 2 & 3 & 1 & SD \\
Marketing & 3 & 2 & 1 & 2 & 1 & $* *$ \\
Sistemas & 4 & 0 & 4 & 4 & 0 & $* *$ \\
Matemática & 5 & 3 & 2 & 2 & 3 & SE \\
Serviço Social & 5 & 5 & 0 & 3 & 2 & SE/SD \\
\hline Geral & 91 & 53 & 48 & 65 & 26 & SD/EV \\
\hline
\end{tabular}

Fonte: Dados da pesquisa

*Amostra não significativa

**Amostra caracterizada por várias ancoras.

Com o intuito de verificar a possível associação entre âncoras com o curso, tendo por base os dados da Tabela 2, e as demais informações adquiridas na folha de respostas anexada ao questionário, as análises a seguir apresentarão os resultados obtidos por curso, sendo que serão discutidos, mais detalhadamente, os cursos que apresentaram resultados e tamanho da amostra mais significativos.

\subsection{Curso de Administração}


A amostra do curso de Administração foi composta por 24 alunos. Apenas 4\% afirmam que o curso não corresponde à sua perspectiva de carreira, já os $96 \%$ restantes afirmam que sim, o curso corresponde às suas perspectivas de carreira. Em relação ao grau de prioridade entre carreira e família, 4\% consideram carreira como prioridade, $29 \%$ consideram família como prioridade e $67 \%$ consideram ambos, carreira e família com o mesmo grau de prioridade.

As âncoras de carreira que predominaram na amostra desse curso foram Estilo de Vida e Serviço e Dedicação a uma causa, as duas representaram a proporção de $42 \%$ da opinião dos respondentes.

As âncoras de menor destaque foram Competência Técnica-Funcional e Competência para o Gerenciamento (Administração Geral), as duas representando 8\% da opinião dos respondentes. O resultado quanto à âncora Competência TécnicaFuncional pode ser justificado pelo fato de compreender indivíduos que valorizam a especialização em sua área de atuação, o que contradiz a visão de um todo organizacional oferecida no curso de Administração. Já a pequena proporção encontrada quanto à âncora Administração Geral foi inesperada para este curso, já que essa âncora abrange pessoas que desejam ascensão hierárquica e valorizam a liderança.

A grande maioria dos entrevistados exerce ou já exerceu algum tipo de atividade remunerada (96\%); sendo que, desses, os que apresentam menor tempo de experiência profissional têm pelo menos dois anos de experiência.Em relação à identidade com o cargo ou profissão atual $78 \%$ se identificam com o que exercem, $18 \%$ não se identificam e $4 \%$ não responderam.

Os que se identificam com o cargo ou profissão atual apresentaram três justificativas que mais se destacaram que foram: o fato de possuírem autonomia na execução de suas funções, as oportunidades de crescimento profissional e a possibilidade de se relacionarem com as pessoas.

Quanto às justificativas expostas pelos entrevistados que não se identificam com o cargo ou profissão atual, a que mais se destacou foi o fato de não ter relação com o curso. Se analisada essa resposta com a baixa frequência da âncora Administração Geral, pode-se considerar essa resposta como uma possível justificativa para o fato, pois estes alunos reiteraram sua falta de identidade ao fato de não desempenharem funções que abrangem a função de administrador.

A dispersão (desvio padrão) para as âncoras observadas é de 1.6, tendo em vista apenas a análise quantitativa, implica dizer que há possibilidade do curso ser caracterizado por outra âncora.

\subsection{Curso de Arquitetura e Urbanismo}

O curso de Arquitetura e Urbanismo foi representado por nove alunos, com idade média de 23 anos, estando distribuídos na faixa etária compreendida de 19 a 38 anos.Todos os alunos afirmaram que o curso corresponde às suas perspectivas de carreira; quanto ao grau de prioridade atribuído a carreira e família, $11 \%$ considera carreira como prioridade, $33 \%$ consideram família como prioridade e $56 \%$ consideram ambos, carreira e família, com o mesmo grau de prioridade.

No que se refere às âncoras de carreira, a que se destacou foi à âncora Criatividade Empreendedora (56\%), levando em consideração as características do curso em questão e a profissão de arquiteto, é possível afirmar que o resultado correspondeu às expectativas esperadas. 
O desvio padrão verificado nessa amostra é de 1.7, esse valor indica que é pequena a variação no resultado obtido.

A porcentagem de alunos com experiência profissional é de $67 \%$, sendo que, desses, 33\% afirmam não se identificarem com o atual cargo ou profissão exercida. A razão predominante como justificativa para essa não identificação se concentrou no fato de que a atual atividade que exercem não tem relação com o curso, foi verificado ainda que a atividade exercida por estes alunos é relacionada à área administrativa.

As justificativas colocadas por aqueles que se identificam com o cargo ou a profissão atual foram a de que têm a possibilidade de exercer atividades que exigem inovação e são desafiadoras.

\subsection{Curso de Gestão Ambiental}

Os participantes da pesquisa que cursam Gestão Ambiental são três alunas, solteiras, com idade média de 22 anos. As três afirmaram que o curso corresponde às suas perspectivas de carreira.

As âncoras encontradas nessa amostra foram: Desafio Puro (67\%) e Segurança e Estabilidade (33\%).

A área de Gestão Ambiental é uma área desafiadora, pois trata de resolução de problemas; mas, em virtude do tamanho da amostra, não é possível caracterizar a âncora encontrada, Desafio Puro, como predominante para esse curso.

As duas respondentes que afirmaram já terem experiências profissionais disseram não estarem identificadas com o atual cargo ou profissão que exercem o motivo reiterado por ambas é o fato da atividade não ter nenhuma relação com o curso escolhido.

\subsection{Curso de Ciências Contábeis}

Representado por 13 alunos, o curso de Ciências Contábeis apresentou uma amostra caracterizada por pesquisados com idade média de 25 anos e todos eles consideram o curso de acordo com a perspectiva de carreira que possuem. A proporção dos alunos que priorizam família é de $67 \%$ e os que priorizam carreira e família igualmente é de $33 \%$.

Observou-se que a âncora predominante foi Estilo de Vida, resultado que pode ser associado ao fato da maioria dessa amostra ser composta por pessoas casadas que consideram a família prioridade à frente de carreira ou carreira e família prioridades equivalentes. Vale ressaltar que essa análise não significa que a escolha por esse curso está relacionada a essa âncora.

Nessa amostra, $100 \%$ possui experiência profissional e $85 \%$ se identifica com a profissão ou cargo ocupado. Esses $85 \%$ enfatizaram a resposta pelo fato de estarem executando algo que se relaciona com o curso e pelo fato de a atividade proporcionar satisfação e realização pessoal. Os $15 \%$ que afirmaram não se identificarem com a profissão atual não apontaram especificamente um motivo que pudesse servir de base para uma justificativa.

O desvio padrão encontrado foi 1.6, o que representa uma pequena dispersão em relação ao resultado.

\subsection{Curso de Direito}


Compuseram a amostra do curso de direito oito alunos.

A partir dos dados coletados, nota-se que houve uma maior frequência da âncora Competência Técnica-Funcional, seguida pela âncora Serviço ou Dedicação a uma Causa, a razão destas âncoras, terem se sobressaído pode ser associada ao fato desses alunos já vislumbrarem especificamente uma profissão, como, por exemplo, advogado, promotor, juiz, delegado. São profissões ligadas ao contato com o público, dedicação a uma causa, especialização em determinadas áreas, características essas que se encontram na definição das âncoras em evidência.

O desvio padrão resultante da amostra do curso de Direito foi de 1.1.

\subsection{Curso de Engenharia Civil}

A amostra analisada foi de 12 alunos, cuja idade média dos representantes é de 24 anos, compreendendo uma faixa de 19 a 35 anos. Os 12 representantes afirmaram que o curso corresponde às suas perspectivas de carreira, sendo que 07 consideram a família prioridade em relação à carreira e 05 colocaram carreira e família com o mesmo grau de prioridade. $\mathrm{O}$ número de representantes com experiência profissional é igual a 09; desses, 05 identificam-se com o cargo ou profissão atual. Quatro âncoras tiveram frequência zero na amostra selecionada do respectivo curso e a âncora de destaque na amostra foi à âncora Desafio Puro, seguida pela âncora Serviço ou Dedicação a uma Causa.

O desvio padrão encontrado foi de grau de dispersão 2, associado com o fator identidade descrito na folha de resposta do questionário, intui-se a possibilidade de alteração no resultado das âncoras.

Dentre os 09 participantes que tem experiência profissional e, atualmente, exercem alguma atividade remunerada, 04 afirmaram não ter identidade com o atual cargo ou profissão exercida, justificando o fato por não desempenharem funções relacionadas ao curso e por serem funções que não exijam o uso de suas competências e habilidades.

Isso levanta a hipótese de que a ausência de experiência profissional na área de engenharia pode ter influenciado o resultado das âncoras, os respondentes podem ter assimilado as respostas apenas em virtude da profissão de engenheiro; mas, a construção de uma profissão nessa área poderia demonstrar características presentes em outra âncora.

\subsection{Curso de História}

O curso de História foi representado por quatro alunos e todos os respondentes afirmaram que o curso corresponde à perspectiva de carreira.

No resultado desse curso predominou a âncora Serviço ou Dedicação a uma Causa (50\%); contudo, o tamanho da amostra e o fato de apenas um respondente ter experiência profissional, abre possibilidades para questionamentos em relação ao resultado no que se refere ao direcionamento da trajetória profissional.

\subsection{Curso de Matemática}


Com uma amostra composta por cinco alunos, o curso de Matemática apresentou a âncora Segurança e Estabilidade com a maior frequência (80\%).

Os resultados da questão identidade com a carreira desses pesquisados indica o resultado da âncora como direcionamento da atual profissão que eles exercem, o que não revela uma relação direta dessa âncora para o curso em si.

\subsection{Curso de Serviço Social}

A amostra do curso de Serviço Social foi composta por cinco alunas. A amostra apresentou empate entre as âncoras Segurança e Estabilidade (40\%), Serviço ou Dedicação a uma Causa (40\%). Qualquer uma dessas âncoras poderia ser representativa para o curso, a âncora Segurança e Estabilidade se as respondentes estiverem decididas à prestação de concurso público para o cargo de Assistência Social, já que o serviço público oferece a estabilidade do vínculo empregatício e, também, considerando a função de uma Assistente Social, justifica-se a presença da âncora Serviço ou Dedicação a uma Causa, pelo contato com as pessoas e a possibilidade de fazer algo em prol da sociedade.

4.10 Demais Cursos (Construção de Edifícios, Marketing e Análise e Desenvolvimento de Sistemas)

O curso de Construção de Edifício teve apenas um representante, não sendo, portanto uma amostra significativa para uma projeção que defina as características de profissionais que queiram construir sua carreira em torno dessa área.

Os cursos de Marketing e Análise e Desenvolvimento de Sistemas não foram caracterizados por nenhuma categoria de âncora específica, além de terem sido representados por uma pequena amostra, três e quatro alunos respectivamente.

\section{Conclusões}

Esse estudo, voltado para implicações do desenvolvimento da área de gestão de pessoas, teve o intuito de verificar entre discentes de curso superior a existência da identidade no processo de construção de carreira e quais as âncoras tem sido determinantes de suas trajetórias profissionais. Buscou-se também verificar relações de âncoras com os cursos que compuseram a amostra. Para demonstrar um resultado mais consistente, variáveis como gênero e família foram averiguadas para uma possível associação com os resultados.

Apesar de verificar o interesse que os jovens têm em construir uma carreira, e visto que $96 \%$ consideram que o curso corresponde à atual perspectiva de carreira que possuem, surpreendentemente, o fator carreira não tem sido a prioridade dos mesmos. Considerando a idade média do público geral - 24 anos - e o fato de $71 \%$ serem solteiros, a dedução levantada seria de que carreira estaria em destaque em relação à vida familiar. Contudo, observou-se que o desejo de se construir uma carreira tendo em vista o equilíbrio com a vida familiar prevaleceu no resultado da pesquisa, um fato que comprova isso é a frequência obtida na âncora Estilo de Vida.

As mulheres, cada vez mais, têm ocupado espaço no mercado de trabalho e têm a necessidade de conciliar vida pessoal com vida profissional. No caso deste estudo, a maioria das representantes do sexo feminino ainda é solteira; porém, segundo Taveira 
(2000), a questão do gênero tem sido um diferencial em termos de orientação de carreira. Até mesmo Schein (1996a), na sequência de sua pesquisa sobre âncoras, levantou a hipótese da âncora Estilo de Vida estar ligada ao gênero, o que pode explicar o resultado geral encontrado no referido estudo, mesmo que as observações do autor não tenham sido feitas tendo por base a realidade brasileira.

Ainda sobre a variável gênero, Hoffman (2004) atenta sobre as disparidades entre homens e mulheres no que tange o comportamento individual de ambos. A autora enfatiza que as diferenças estão pautadas em aspectos culturais, sociais e biológicos de ambos, sendo a mulher mais sensível ao universo simbólico e espiritual da espécie humana, e o homem focado no plano físico, sendo mais disposto a correr riscos.

Baseando-se nos estudos de Schein (1996a), os resultados evidenciaram que os alunos valorizam equilíbrio entre carreira, vida pessoal e familiar (Estilo de Vida) e desejam que suas funções possam contribuir para a sociedade, prezando pelo reconhecimento organizacional e remunerações justas por sua contribuição (Serviço ou Dedicação a uma Causa).

A âncora de maior destaque, Serviço ou Dedicação a uma Causa, está mais relacionada com a questão da identidade com a carreira; pois destacou-se nas respostas dos pesquisados que possuem experiência profissional e estão identificados com o atual cargo ocupado ou profissão.

Verificou-se que a identidade tem sido muito valorizada pelo público pesquisado, estando caracterizada, sob a perspectiva desse, por profissões que ofereçam satisfação pessoal, oportunidades de crescimento, autonomia, possibilidade de lidar com pessoas, flexibilidade e relacionem-se com a área de formação dos mesmos. A remuneração foi o fator menos relevante nessa área.

Malvezzi (2000) e Araújo (2009) dão ênfase à importância da identidade com a carreira, afirmando ser um fator que torna complexo a gestão de pessoas, já que identidade se relaciona com o envolvimento do indivíduo no trabalho.

A âncora menos evidente, Administração Geral, caracterizou apenas um respondente, apesar da maioria da amostra ser de alunos do curso de Administração. $\mathrm{O}$ motivo pode ser o fato de $38 \%$ dos alunos estarem na faixa de 1 a 5 anos de experiência profissional, ou seja a pequena experiência profissional e o fato da maioria dos representantes serem ainda muito jovens (48\% estão na faixa de 18 a 21 anos) pode afetar o resultado de uma âncora mais consistente (Schein, 1996a). A ausência de uma responsabilidade em se sustentar ou sustentar uma família pode ter levado os pesquisados a idealizar atrativos em uma profissão futura sem se preocupar com uma carreira mais consolidada.

Schein (1996a) argumenta que a âncora Serviço ou Dedicação a uma Causa é aplicada àqueles que desejam trabalhar para as pessoas, sentem-se satisfeitos em prestar um serviço para a sociedade e não consideram o dinheiro em si, como um fator determinante, apesar de desejarem remunerações justas. Querem ser promovidos e valorizados por sua contribuição, almejando sempre cargos que lhes proporcionem autonomia e poder de decisão.

Dos cursos que foram caracterizados por essa âncora, o que mais tem o perfil dessa categoria é o curso de Serviço Social, também podendo ser aplicada ao curso de História. Como esses cursos foram representados por poucos alunos, fica a inquietação da possibilidade de variação do resultado observado. O resultado dessa âncora para o curso de Administração pode ser justificado em virtude das respostas pessoais dos 
pesquisados quanto à identidade com o atual cargo ou profissão exercida, uma vez que os respondentes valorizaram o fato de trabalhar atendendo pessoas.

A âncora Estilo de Vida é definida por Schein (1996a) como aquela voltada para as pessoas que desejam integrar carreira, necessidades individuais e vida familiar. Essas pessoas tendem a ser resistentes às mudanças geográficas, uma vez que isso poderá interferir em suas necessidades individuais e vida familiar. A carreira em si não é o foco daqueles que estão ancorados nessa categoria e questões como oportunidades de crescimento, remuneração e tipo de trabalho variam em função da necessidade do indivíduo.

Essa âncora foi destaque no curso de Administração e Ciências Contábeis, ambos provavelmente se enquadraram nessa categoria em virtude da presença do número maior de mulheres na amostra e o curso de Ciências Contábeis, além disso, por ter a amostra composta pela maioria de pessoas casadas.

Os ancorados na categoria Criatividade Empreendedora buscam desempenhar atividades que possibilitem expor sua criatividade e têm necessidade de criar algo fruto de seus esforços (Schein, 1996a). O resultado obtido do curso de Arquitetura e Urbanismo para essa âncora era esperado em virtude das características do mesmo.

Os cursos de Matemática e Serviço Social destacaram a âncora Segurança e Estabilidade. Essa âncora abrange pessoas que priorizam o vínculo empregatício estável e a segurança financeira em suas carreiras, muitas vezes pensando no futuro como aposentados ou na educação dos filhos (Schein, 1996a). Os dois cursos são muito voltados para a área de prestação de serviço público, por isso compreende-se o destaque na amostra.

As áreas que envolvem os cursos de Gestão Ambiental, Construção de Edifícios e Engenharia Civil podem apresentar grandes desafios aos profissionais. Lembrando que a âncora Desafio Puro engloba pessoas competitivas e que se dedicam a transpor obstáculos difíceis e lidar com situações adversas (Schein, 1996a), sendo possível fazer associação da âncora com os cursos.

A âncora Competência Técnica-Funcional engloba profissionais que organizam suas carreiras em torno de suas especialidades (Schein, 1996a). Profissionais da área de Direito têm tendência a se especializarem em uma profissão, logo a âncora retrata bem o curso.

A associação de âncoras por curso apresentou, em algumas amostras, resultados significativos e até mesmo curiosos; porém, percebeu-se que, para afirmações mais consistentes, seria necessária uma análise em amostras maiores.

Além do tamanho da amostra, o presente estudo apresentou como limitação o fato de não ter separado os alunos por períodos, pois é possível que a perspectivas e as âncoras de carreira apresentassem alterações em relação à avaliação de ingressantes e concluintes. Uma sugestão para continuidade desta pesquisa é uma nova aplicação, considerando esse aspecto.

Apesar das limitações apresentadas, foi possível verificar as âncoras determinantes no direcionamento de trajetórias profissionais de alunos de curso superior, bem como a percepção da existência da identidade com a carreira pelos alunos que possuem experiência profissional.

Entre resultados esperados e intrigantes, de forma geral, o resultado da pesquisa revelou que carreira não pode e nem deve mais ser vista de maneira isolada em virtude do peso de diversas variáveis. No caso deste estudo, sobressaíram-se as variáveis gênero e família. Hoffmann (2004, p. 23) afirma que, "uma empresa que aborda com 
profundidade a questão de gênero saberá, certamente, aproveitar melhor o que cada colaborador (mulheres e homens) pode oferecer.

Uma implicação que deve ser considerada é que a área de Gestão de Pessoas precisa dar mais ênfase a essa complexidade advinda dos novos tipos de carreira e da dimensão adquirida da identidade com a profissão para o futuro organizacional, pois o capital intelectual é o diferencial para uma organização bem sucedida. As organizações precisam urgentemente considerar alternativas para atender às perspectivas de carreira, pois a responsabilidade do plano de carreira transferida para o indivíduo torna-se a retenção do profissional mais difícil.

Tendo em vista o destaque que a carreira tem adquirido, sugere-se que novas pesquisas na área sejam realizadas com base em âncoras, pois se constatou que os resultados desse método contribuem para o meio acadêmico e também para as organizações. Os próprios pesquisados tendem a repensar mais sobre suas trajetórias profissionais ao analisarem as categorias em que se enquadram.

\section{Referências}

Araújo, Luis César G. de. (2009). Gestão de pessoas: estratégias e integração organizacional. 2. ed. São Paulo: Atlas.

Bertucci, Janete Lara de Oliveira. (2009). Metodologia básica para elaboração de trabalhos de conclusão de cursos (TCC): ênfase na elaboração de TCC de pósgraduação Lato Sensu. 1. ed. São Paulo: Atlas.

Brown, S. D., \& Lent, R. W. (2008). Handbook of counseling psychology. New Jersey: John Wiley \& Sons, Inc.

Chanlat, Jean-François. (1995). Quais carreiras e para qual sociedade? In: Revista de Administração de Empresas, v. 36, n.1. p. 13-20, nov./dez.

Dutra, Joel Souza.(1996). Administração de carreiras: uma proposta para repensar a gestão de pessoas. São Paulo; Atlas.

Fonseca, Jairo Simon da, \& Martins, Gilberto de Andrade. (2008). Curso de Estatística. 6. ed. São Paulo: Atlas.

Gil, Antonio Carlos. (1999). Métodos e técnicas de pesquisa social. 5. ed. São Paulo: Atlas.

Hall, Douglas T.(1976). Career in organizations. Califórnia: Goodyear.

Hoffmann, Gleise, H. (2004). Responsabilidade social e a questão de gênero. In: Revista FAE BUSINESS. Curitiba:n ${ }^{\circ}$, set..

Irisvideo. (1995). Planejamento de carreira: definindo hoje um futuro profissional de sucesso. Direção e edição: Cassio Maradei. Direção geral: Cassandra Schaly. Apresentação: Gisela Kassoy. São Paulo: BTC/Suma Econômica, 1 videocassete (56 $\min )$. 
Kilimnik, Zélia Miranda. (2000). Trajetórias e transições de carreiras profissionais em recursos humanos. Belo Horizonte: UFMG/FACE, Tese de Doutorado em Administração.

Lucena, Maria Diva da Salete. (1999). Planejamento de recursos humanos. São Paulo: Atlas.

Malvezzi, Sigmar.(2000). A construção da identidade profissional no modelo emergente de carreira. In: Revista Organizações e Sociedade. v.7, n.17, jan/abr, Salvador: UFBA.

Milkovich, George T., \& Boudreau, John W. (2000). Administração de recursos humanos. São Paulo: Atlas.

O’donnel, Ken. (2006). Valores Humanos no Trabalho: da parede para a prática. São Paulo: Editora Gente.

Robbins, S. P. (1998). Comportamento Organizacional. Rio de Janeiro: Livros Técnicos e Científicos.

Schein, Edgar H. (1978). Career dynamics. Reading, MA: Addison-Wesley.

(1996a). Identidade Profissional: como ajustar as suas inclinações a suas opções de trabalho. São Paulo: Nobel.

. (1996b). Career anchors revisited: implications for career development in the $21^{\text {st }}$ century. Academy of Management Executive, v.0, n.0,. Disponível em: <http://www.jstor.org/pss/4165355>. Acesso em: 10 set. 2012.

Taveira, M. C. (2000). Exploração e desenvolvimento vocacional de jovens. Braga, Portugal: CEEP. 